\title{
Matlab/Simulink based modeling and simulation of decoupled power control for DFIG operating in wind generation systems
}

\author{
Abdellatif Kasbi*, Abderrafii Rahali \\ Laboratory of Electronics, Automatics and Biotechnology, Faculty of Sciences, Moulay Ismaïl University, \\ B.P. 11201, Zitoune, Meknes, Morocco
}

\begin{abstract}
This paper appraises the performances of two control scenarios, for doubly fed induction generator (DFIG) operating in wind generation system (WGS), which are the direct decoupled control (DDC) and indirect decoupled control (IDC). Both control scenarios studied combines vector control and Maximum Power Point Tracking (MPPT) control theory so as to maximize the captured power through wind turbine. Modeling of DFIG based WGS and details of both control scenarios have been presented, a proportional integral controller is employed in the active and reactive power control loops for both control methods. The performance of the both control scenarios in terms of power reference tracking and robustness against machine parameters inconstancy has been shown, analyzed and compared, which can afford a reference to the operators and engineers of a wind farm. All simulations have been implemented via MATLAB/Simulink.
\end{abstract}

Keywords-DFIG, WGS, DDC, IDC, vector control, MPPT.

\section{INTRODUCTION}

$\mathrm{I}$ $\mathrm{N}$ recent years, the use of renewable energy sources have enticed the serious interest because reserves of conventional sources energy are limited and a number of problems related with their employment raised, such as environment contamination, enormous grid requirements. Countries of the whole world are forced for the alternative energy sources such as solar energy, wind power and small hydro-electric power [1], the sustainable power sources are one of the promising future energy sources. All major politicians, decision makers, leaders of industry and economy recognized worldwide the great potentials in sustainable energies. This increased the efforts, principally in developed countries of world, in research area and new installations employing renewable and clean energies which are spectacularly accelerating [2]. Nowadays, wind power can contend with any other source of energy as a free of cost and non-polluting technique of harnessing natural energy. Recently, intensive research has

\footnotetext{
* Corresponding author: kasbi1.abdellatif@gmail.com (A. Kasbi)
}

being carried out more and more in most of the countries and resulting the various WGS configurations. The most popular wind system is the grid connected DFIG-based wind turbine. This variable speed DFIG generator was adopted to improve the efficiency, power rating, cost benefit effectiveness etc. [3], [4]. Indeed, this wind system type, using DFIG generator and two converters in back-to-back mode that connects the rotor of generator with grid, has many advantages. For example, the power converters employed are dimensioned to pass just a fraction of the total generated power and consequently, this characteristic allows reducing losses in the power electronics components, maximizing power capture, smoothing the power transmission and less mechanical stresses [5]. On the other hand, by dint of the high variability nature of wind speed, DFIG-based variable speed WGS are a very efficient way for wind energy gathering [4], because this provides better flexibility in power conversion and also more stability in voltage and frequency control in the power systems to which these generators are connected [6]. In addition to that, due to variable speed operation, total energy output is much more important in case of DFIG-based WGS, so the capacity utilization factor is improved and cost of per unit energy is reduced [7].

The performances and power generation depends not only on the DFIG generator, but also the manner in which the converters in back-to-back mode are controlled. Concerning this considered wind system, the rotor side converter (RSC) controls the active power and reactive power produced by the machine. As the grid side converter (GSC), it controls the DC bus voltage and power factor grid side [2], [8].

Many researchers [2], [3], [8] have studied the DFIG-based wind energy conversion system. In this context, the current paper is focused on the study, modeling and control of WGS based on a 1.5 MW DFIG. With a view to control the active and reactive power exchanged between the DFIG-generator and the grid, an itemized dynamic model of a DFIG generator based WGS grid-connected is described in the $\mathrm{d}-\mathrm{q}$, synchronous rotating reference frame by controlling the RSC with methodology of control based on the vector control approach (stator flux orientation control strategy). The main objective of control is to obtain the active and reactive generated powers equal to the reference values. The control of 
this system is applied to achieve the decoupled control of stator active and reactive powers exchanged among the DFIGgenerator and the grid to ensure a MPPT. Indeed, two control scenarios are applied to the DFIG as follows: one is DDC that performs the regulation directly on the powers without taking into consideration the existing term couplings between the active and reactive powers, and the other is the IDC which is done through two cascading loops, an external loop of active power (reactive power) control and internal loop of rotor current control in the $\mathrm{q}$ axis (d axis). Our system is simulated and the performances of the both control scenarios are compared in terms of reference tracking and robustness facing generator parameters inconstancy. The remainder of this paper is organized as follows. After the introduction, Section II presents the dynamics of the variable speed WGS based on DFIG-generator, it also presents the MPPT control strategy. The DDC and IDC scenarios based on vector control approach for control of DFIG-generator are discussed in Section III. Section IV presents the analysis and performances evaluation of both control scenarios using the classical proportional- integral controller by means of real time simulations. Finally the conclusion is made in Section V.

\section{MODELING OF VARIABLE SPEED WGS}

DFIG is a typical electric generator used in the generation applications of the electrical power and more particularly in wind turbines [9]. The rotor speed of DFIG is varied by controlling the amount of power transferred to the rotor through a bi-directional voltage-source back-to-back power converter. In wind energy applications the system needs a gearbox to accelerate the turbine rotation into the generator [10]. The clarified schematic configuration of the WGS based on a DFIG generator studied in this paper is shown in Fig. 1. In this figure, the mechanical energy is produced by the turbine and provided to rotor of DFIG via gear box. The stator winding of the DFIG is directly connected to the grid, whereas the winding of rotor is fed by back-to-back pulse width modulation (PWM) converters.

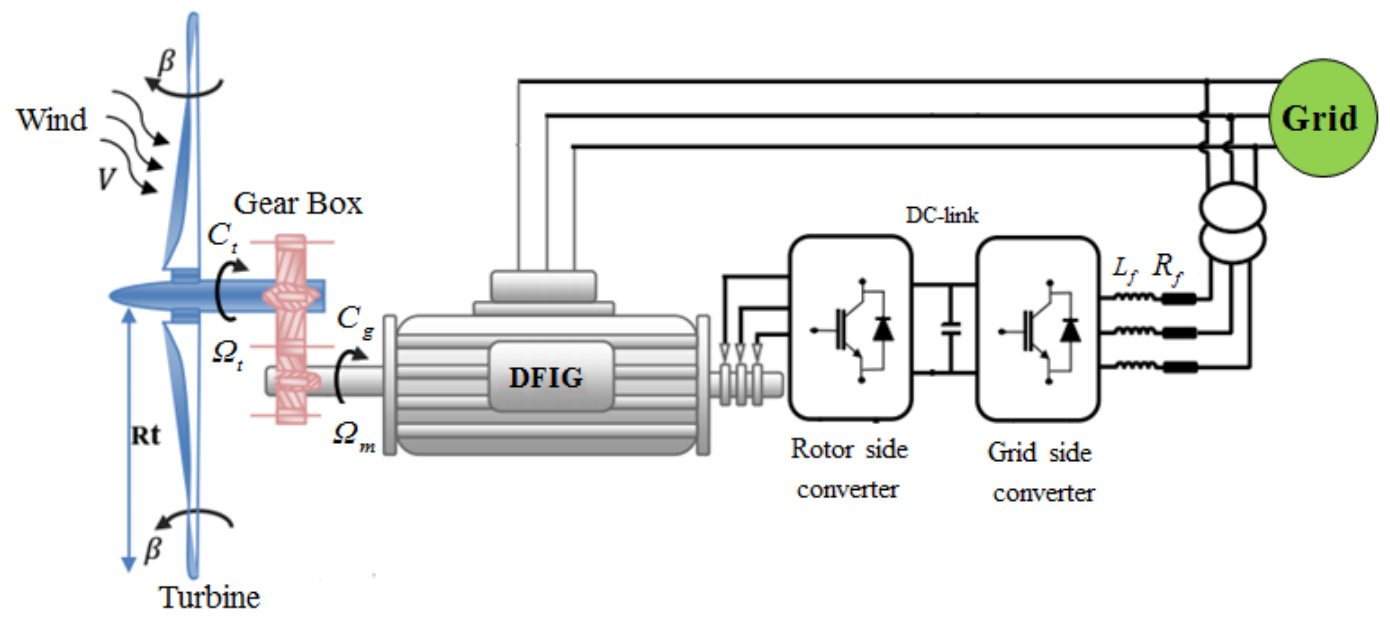

Fig. 1 Configuration of WGS based on DFIG

\section{A. Model of Wind Turbine}

In accordance with the Betz theory, the extracted power through a horizontal axis wind turbine is expressed by [11], [12]:

$$
\begin{aligned}
P_{t} & =0.5 \rho S V^{3} C_{p}(\lambda, \beta) \\
\lambda & =\frac{\Omega_{\mathrm{t}} \cdot R}{V}
\end{aligned}
$$

where $\rho$ the air density $\left(\rho=1.225 \mathrm{~kg} / \mathrm{m}^{3}\right.$ at atmospheric pressure), $\mathrm{S}$ the surface swept by turbine blades $\left[\mathrm{m}^{2}\right], \mathrm{V}$ is wind speed $[\mathrm{m} / \mathrm{s}], \mathrm{C}_{\mathrm{p}}$ is power coefficient, $\lambda$ is tip speed ratio, $\beta$ the pitch angle [deg], $\mathrm{R}$ the blade length $[\mathrm{m}]$. and $\Omega_{\mathrm{t}}$ turbine speed [tr/min].

The aerodynamic torque produced by the turbine is expressed as [12]:

$$
\mathrm{C}_{\mathrm{t}}=\frac{\mathrm{P}_{\mathrm{t}}}{\Omega_{\mathrm{t}}}=\frac{0.5 \rho \pi \mathrm{R}^{3} \mathrm{~V}^{2} \mathrm{C}_{\mathrm{p}}(\lambda, \beta)}{\lambda}
$$

The Gear Box adapts the speed of the turbine to the speed of the generator; it is modeled by the following mathematical relations:

$$
\mathrm{C}_{\mathrm{g}}=\frac{\mathrm{C}_{\mathrm{t}}}{\mathrm{G}}, \quad \Omega_{\mathrm{t}}=\frac{\Omega_{\mathrm{m}}}{\mathrm{G}}
$$

The following equation models the generator shaft:

$$
J \frac{d \Omega_{m}}{d t}=C_{m}=C_{g}-C_{e m}-f_{v i s} \Omega_{m}
$$

where J: Total inertia that appears on the shaft of the generator, $C_{e m}$ : Torque electromagnetic produced by the generator, $C_{g}$ : Torque from the Gear Box, $f_{v i s}$ : Viscous friction coefficient, $\Omega_{m}$ : Mechanical angular speed of the generator, $C_{m}$ : Total mechanical torque on the axis of the 
generator.

As [13], the approximate expression of the power coefficient that we used in this paper is shown as:

$$
C_{p}(\lambda, \beta)=0.5176\left(\frac{116}{\lambda_{i}}-0.4 \beta-5\right) \exp \left(\frac{21}{\lambda_{i}}\right)+0.0068 \lambda
$$

with:

$$
\frac{1}{\lambda_{i}}=\frac{1}{\lambda+0.08 \beta}-\frac{0.035}{\beta^{3}+1}
$$

Fig. 2 shows the evolution of the power coefficient in function of the parameters $\lambda$ and $\beta$. This curve is characterized by the optimum point: for the pitch angle $\beta=0^{\circ}$, it has a unique maximum point of $\mathrm{C}_{\text {pmax }}=0.48$ at $\lambda_{\text {opt }}=8.1$; this value represents the Betz limit, which is the point corresponding to the maximum power coefficient $\mathrm{C}_{\mathrm{p}}$ and consequently, the most mechanical power can be extracted by the wind turbine. To conserve $\lambda$ at its optimum value and consequently maximize the captured power, it is necessary to vary the speed of rotation of the turbine in a linear manner with the wind speed pursuant to (2).

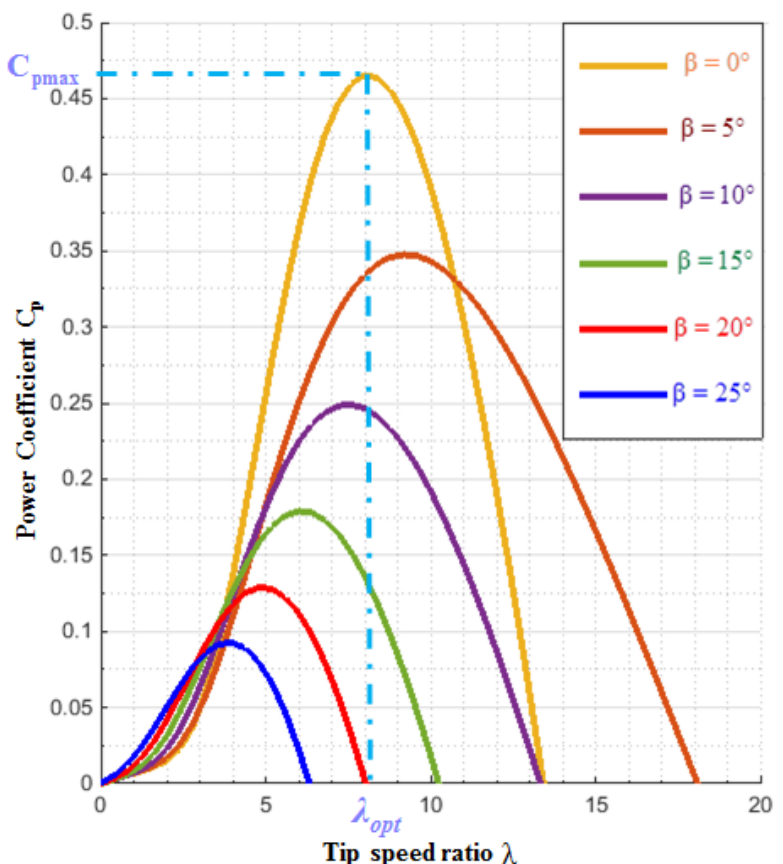

Fig. 2 Power coefficient in function of tip speed for different Pitch angle

\section{B. Maximum Wind Power Extraction Strategy}

Depending on the wind aerodynamic conditions, there exist optimal operating points which may allow the extraction of maximum power. The power captured by the wind turbine can be substantially maximized by adjusting the coefficient $C_{p}$ which represents the turbine efficiency to convert wind kinetic power into mechanical power and it depends on the rotor speed of DFIG-generator (i.e., Tip Speed Ratio $\lambda$ ). It is necessary to establish control strategy in order to maximize the power extracted by adapting the speed of the turbine to an optimal value. The characteristic of the optimum aerodynamic power of a wind turbine is presented in Fig. 3. The position of the points representing the maximum power can be determined and tracked by adapting the speed of the turbine (dotted curve). Thus, to maximize the converted power, the turbine speed must appropriate to wind speed.



Fig. 3 Optimum operating characteristics of the turbine

So as to extract the extreme power of the incident wind energy, it requires incessantly the adjustment of the rotational speed of the wind turbine. As we mentioned previously, for $\lambda=8.1$ and $\beta=0^{\circ}$ the mechanical speed turbine corresponding is optimal. The rotor speed of DFIG generator is applied as the desired value for a proportional-integral controller. The output signal of the latter determines the control signal which is the electromagnetic torque that should be exercised to the generator to operate at its optimal speed. The torque thus determined by the controller is used as a reference torque of the turbine model, as shown in Fig. 4. From the relation $\lambda=\Omega_{\mathrm{t}} \cdot \mathrm{R} / \mathrm{v}$, the mechanical power is the maximum if the maximum value of the coefficient $C_{p}$ is reached. This is obtained if the tip speed ratio $\lambda$ remains equal to its optimal value $\lambda_{\text {opt }}$ (with $\beta$ constant and equal to $0^{\circ}$ ). Therefore, the mechanical speed reference of turbine is obtained from [11]:

$$
\Omega_{\mathrm{t}}^{\mathrm{ref}}=\frac{\lambda_{\mathrm{opt}} \cdot V}{R}
$$

The relation between the wind turbine speed and the generator speed is as follows:

$$
\Omega_{\mathrm{m}}^{\mathrm{ref}}=\mathrm{G} \cdot \Omega_{\mathrm{t}}^{\mathrm{ref}}
$$

The diagram of the turbine model with the control MPPT is represented in Fig. 4. This control theory should adjust the electromagnetic torque on the DFIG shaft so as to fix the 
rotational speed $\Omega_{\mathrm{m}}$ of the latter at a reference speed $\Omega_{\mathrm{m}}^{\mathrm{ref}}$. A PI regulator makes it possible to control the speed of rotation and to attenuate the effect of the torque $\mathrm{C}_{\mathrm{g}}$, which is

reference is defined as:

$$
\mathrm{C}_{\mathrm{em}}^{\mathrm{ref}}=\mathrm{K}_{\mathrm{p}}\left(\Omega_{\mathrm{m}}^{\mathrm{ref}}-\Omega_{\mathrm{m}}\right)+\mathrm{K}_{\mathrm{i}} \int\left(\Omega_{\mathrm{m}}^{\mathrm{ref}}-\Omega_{\mathrm{m}}\right) d t
$$
considered as a disturbance. The electromagnetic torque $\mathrm{C}_{\mathrm{em}}^{\mathrm{ref}}$

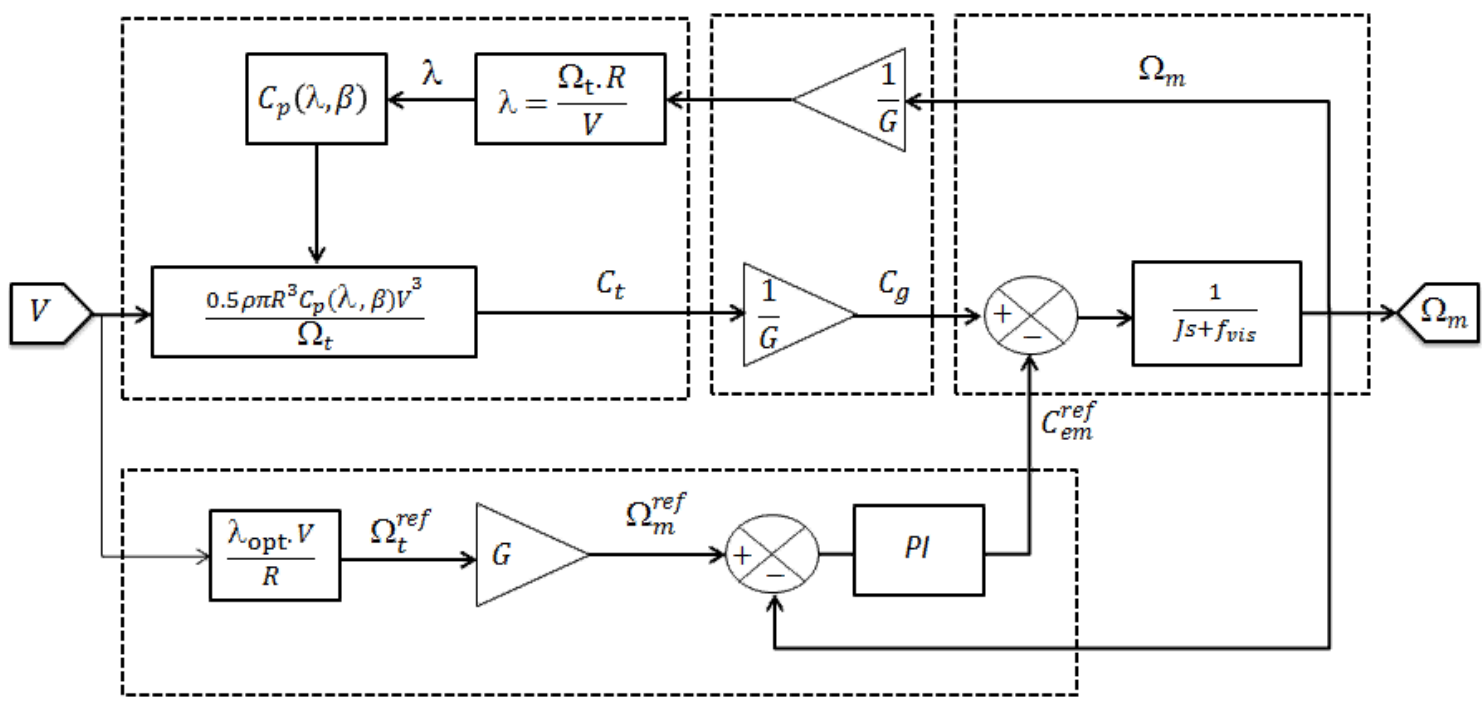

Fig. 4 MPPT control architecture

At this stage we present design of the speed proportionalintegral (PI) controller: From Fig. 5, the transfer function of closed-loop for the system is defined by:

$$
\begin{aligned}
& F(s)=\frac{\left(K_{p}+\frac{K_{i}}{s}\right) \frac{1}{J s+f_{v i s}}}{1+\left(K_{p}+\frac{K_{i}}{s}\right) \frac{1}{J s+f_{v i s}}} \\
& F(s)=\frac{K_{p} s+K_{i}}{J s^{2}+\left(K_{p}+f_{v i s}\right) s+K_{i}}
\end{aligned}
$$

This transfer function which is a second order function could be written as follows:

$$
F(s)=\frac{1}{J} \frac{K_{p} s+K_{i}}{s^{2}+2 \xi \omega_{n} s+\omega_{n}^{2}}
$$

From the two previous equations (12) and (13), the values of the proportional and the integral gains could be calculated easily using the identification method.

$$
\left\{\begin{array}{c}
K_{i}=J \omega_{n}^{2} \\
K_{p}=2 J \xi \omega_{n}-f_{v i s}
\end{array}\right.
$$

$\xi$ is the damping ratio; $\omega_{n}$ is the undamped natural frequency.

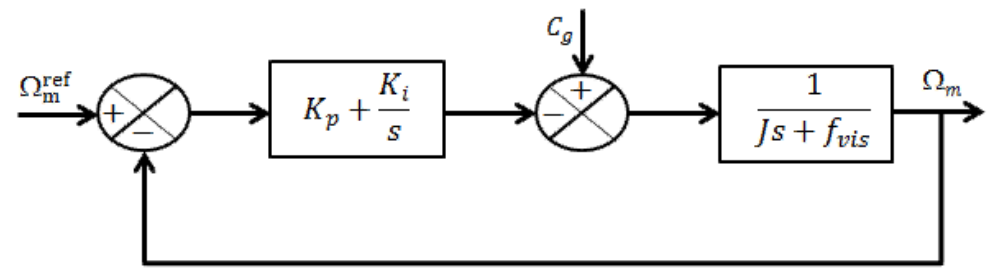

Fig. 5 The speed proportional-integral controller

\section{C.Modeling of DFIG-Generator}

In order to elaborate both control scenarios, a model of the DFIG was established in the $\mathrm{d}-\mathrm{q}$ Park reference frame according to the stator flux orientation control strategy.

\section{a. Model of DFIG in Park Reference}

The model of the DFIG in the Park reference d- $\mathrm{q}$ is given in the following equations [10], [14]:

Direct and quadrature stator voltages:

$$
\left\{\begin{array}{l}
V_{s d}=R_{s} I_{s d}+\frac{d \varphi_{s d}}{d t}-\omega_{s} \varphi_{s q} \\
V_{s q}=R_{s} I_{s q}+\frac{d \varphi_{s q}}{d t}+\omega_{s} \varphi_{s d}
\end{array}\right.
$$

Direct and quadrature rotor voltages:

$$
\left\{\begin{array}{l}
V_{r d}=R_{r} I_{r d}+\frac{d \varphi_{r d}}{d t}-\left(\omega_{s}-\omega\right) \varphi_{r q} \\
V_{r q}=R_{r} I_{r q}+\frac{d \varphi_{r q}}{d t}+\left(\omega_{s}-\omega\right) \varphi_{r d}
\end{array}\right.
$$

Direct and quadrate stator and rotor flux: 


$$
\left\{\begin{array}{l}
\varphi_{s d}=L_{s} I_{s d}+L_{m} I_{r d} \\
\varphi_{s q}=L_{s} I_{s q}+L_{m} I_{r q} \\
\varphi_{r d}=L_{m} I_{s d}+L_{r} I_{r d} \\
\varphi_{r q}=L_{m} I_{s q}+L_{r} I_{r q}
\end{array}\right.
$$

where $L_{s}, L_{r}$ and $L_{m}$ stator and rotor per phase winding and magnetizing inductances, $R_{s}$ and $R_{r}$ are respectively the stator and rotor phase resistances; $\omega=p . \Omega_{m}$ is the electrical speed and $p$ is the pair pole number.

The electromagnetic torque is as follows:

$$
C_{e m}=p\left(I_{s q} \varphi_{s d}-I_{s d} \varphi_{s q}\right)
$$

Stator active and reactive powers are given as:

$$
\left\{\begin{array}{l}
P_{s}=\left(V_{s d} I_{s d}+V_{s q} I_{s q}\right) \\
Q_{s}=\left(V_{s q} I_{s d}-V_{s d} I_{s q}\right)
\end{array}\right.
$$

\section{b. Modeling of DFIG with Stator Field Oriented}

One can see in (17), the strong coupling between the fluxes and the currents. Indeed, the electromagnetic torque is the crossed product between the fluxes and the stator currents, which makes the control of the DFIG particularly difficult. To simplify, one should approximate its model to that of the DC machine which has the advantage of having a natural decoupling between the flux and the current [15]. For DFIG machine, the decoupling can be achieved by the flux orientation technique. The orientation of the flux along the direct axis of the Park reference is mathematically translated as follows:

$$
\varphi_{s d}=\varphi_{s} \quad \text { and } \quad \varphi_{s q}=0
$$

Under this hypothesis of the orientation of the stator flux, the expression of torque would become:

$$
C_{e m}=p \frac{L_{m}}{L_{s}} \varphi_{s} I_{r q}
$$

The stator resistance of the DFIG machine is neglected, and the stator flux $\varphi_{s}$ set aligned with the d axis and assumed to be constant (it is the case of a powerful and stable grid) [14]. The rotor-side converter is controlled in a synchronously rotating $d, q$ axis frame, with the d-axis oriented along the stator flux vector position (Fig. 6).

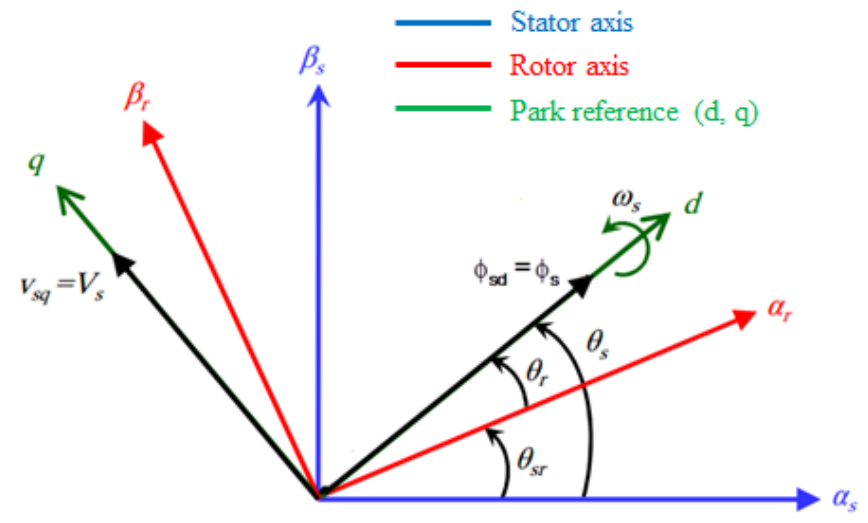

Fig. 6 Orientation of stator flux on the d-axis

The direct and quadrature voltages flux and currents and stator active and reactive power can be simplified as:

$$
\begin{aligned}
& \left\{\begin{array}{c}
V_{s d}=0 \\
V_{s q}=V_{s}=\omega_{s} \varphi_{s}
\end{array}\right. \\
& \left\{\begin{array}{c}
\varphi_{s}=L_{s} I_{s d}+L_{m} I_{r d} \\
\varphi_{s q}=0=L_{s} I_{s q}+L_{m} I_{r q}
\end{array}\right. \\
& \left\{\begin{array}{l}
P_{s}=V_{s} I_{s q} \\
Q_{s}=V_{s} I_{s d}
\end{array}\right.
\end{aligned}
$$

From the system of equations (23), we can establish the link between the stator and rotor currents:

$$
\left\{\begin{array}{c}
I_{s d}=-\frac{L_{m} I_{r d}}{L_{s}}+\frac{\varphi_{s}}{L_{s}} \\
I_{s q}=-\frac{L_{m} I_{r q}}{L_{s}}
\end{array}\right.
$$

Hence, the stator active and reactive powers can be written as:

$$
\left\{\begin{array}{c}
P_{s}=-\frac{V_{s} L_{m}}{L_{s}} I_{r q} \\
Q_{s}=-\frac{V_{s} L_{m}}{L_{s}} I_{r d}+\frac{V_{s} \varphi_{s}}{L_{s}}
\end{array}\right.
$$

As a result, the active and reactive powers are respectively controlled by means of $I_{r q}$ and $I_{r d}$. We could express the rotor voltages in accordion to the rotor currents:

$$
\left\{\begin{array}{c}
V_{r d}=R_{s} I_{r d}+\left(L_{r}-\frac{L_{m}^{2}}{L_{s}}\right) \frac{d I_{r d}}{d t}+C_{d} \\
V_{r q}=R_{s} I_{r q}+\left(L_{r}-\frac{L_{m}^{2}}{L_{s}}\right) \frac{d I_{r q}}{d t}+C_{q}+g \frac{L_{m} V_{s}}{L_{s}}
\end{array}\right.
$$

where $V_{s}$ is the stator voltage magnitude assumed to be constant and $g$ is the slip range, its expression is defined as:

$$
g=\left(\omega_{s}-\omega\right) / \omega_{s}
$$

$C_{d}$ and $C_{q}$ are the coupling terms between the $d$ axis and $q$ axis: 


$$
\left\{\begin{array}{c}
C_{d}=-g \omega_{s}\left(L_{r}-\frac{L_{m}^{2}}{L_{s}}\right) I_{r q}=-g \omega_{s} \sigma L_{r} I_{r q} \\
C_{q}=g \omega_{s}\left(L_{r}-\frac{L_{m}^{2}}{L_{s}}\right) I_{r d}=g \omega_{s} \sigma L_{r} I_{r d}
\end{array}\right.
$$

where $\sigma=1-\frac{\mathrm{L}_{\mathrm{m}}^{2}}{\mathrm{~L}_{\mathrm{s}} \mathrm{L}_{\mathrm{r}}}$ : the dispersion coefficient of the DFIG.

The electromotive forces respectively appear in the direct and quadrature axes designated in $\mathrm{fem}_{d}$ and $\mathrm{fem}_{q}$.

$$
\left\{\begin{array}{c}
\text { fem }_{d}=\frac{V_{s}^{2}}{\omega_{s} L_{s}} \\
\text { fem }_{q}=g \frac{L_{m} V_{s}}{L_{s}}
\end{array}\right.
$$

From (29) and (30), we can rewrite the rotor voltages as:

$$
\left\{\begin{array}{c}
V_{r d}=R_{s} I_{r d}+\sigma L_{r} \frac{d I_{r d}}{d t}+C_{d} \\
V_{r q}=R_{s} I_{r q}+\sigma L_{r} \frac{d I_{r q}}{d t}+C_{q}+f e m_{q}
\end{array}\right.
$$

According to the equations that we have just put in place, we can establish the link between the voltages applied to the rotor of the DFIG and the stator powers that it generates. Fig. 7 describes the block diagram of the simplified electrical system to control. In this block diagram, $V_{r d}$ and $V_{r q}$ are the direct and quadrature components of the rotor voltages, which are imposed on the generator to obtain the desired rotor currents.



Fig. 7 Simplified electrical system to control

\section{DeCOUPLed Power CONTROL OF DFIG By VeCtor CONTROL APPROACH}

In order to control the energy exchanges between the DFIG and the grid, two special control scenarios have been designed to achieve this goal. In the last three decades, vector control approach to control the converters has been analyzed and discussed in the literature, e.g. [16]-[19]. The current control loops and the choice of the reference frame are necessary in this control method and can be implemented in different ways. The architecture of control of the RSC, controlled by the sinetriangle pulse width modulation (ST-PWM) to achieve a decoupled control of the active and reactive power, is illustrated in Fig. 8. It is built on the three phase model of the electromechanical conversion chain of wind energy system [20]. 


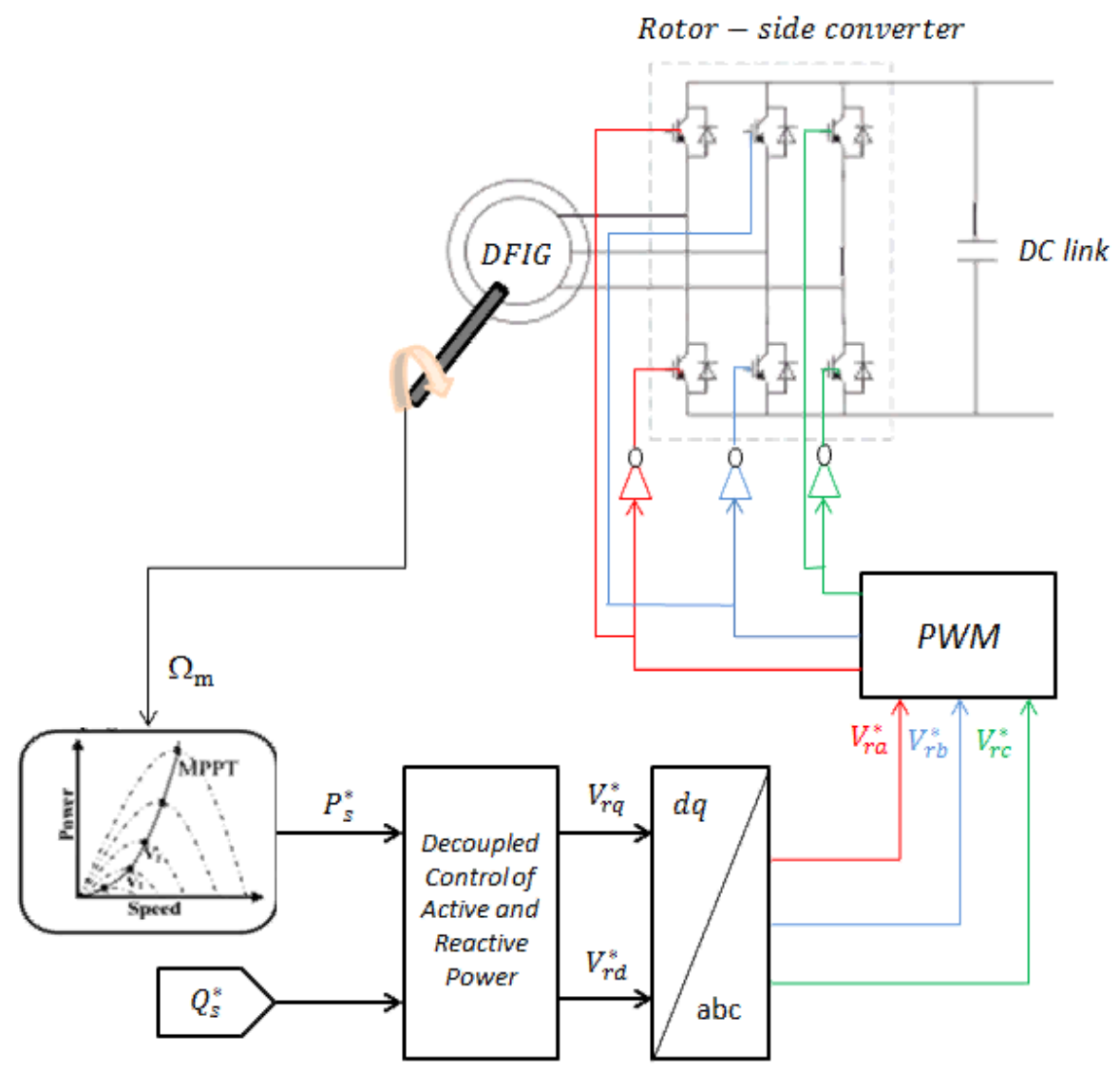

Fig. 8 RSC control diagram

\section{A. DDC Scenario}

The DDC scenario is based on directed control of the active and reactive powers of the generator such as the power regulators directly control the voltages applied to rotor of the DFIG generator. This method consists in neglecting the terms of coupling between the two axes control because of the low value of the slip $g$ and setting up an independent regulator proportional-integral on each axis to independently control the active and reactive powers. The RSC control diagram is depicted in Fig. 9.

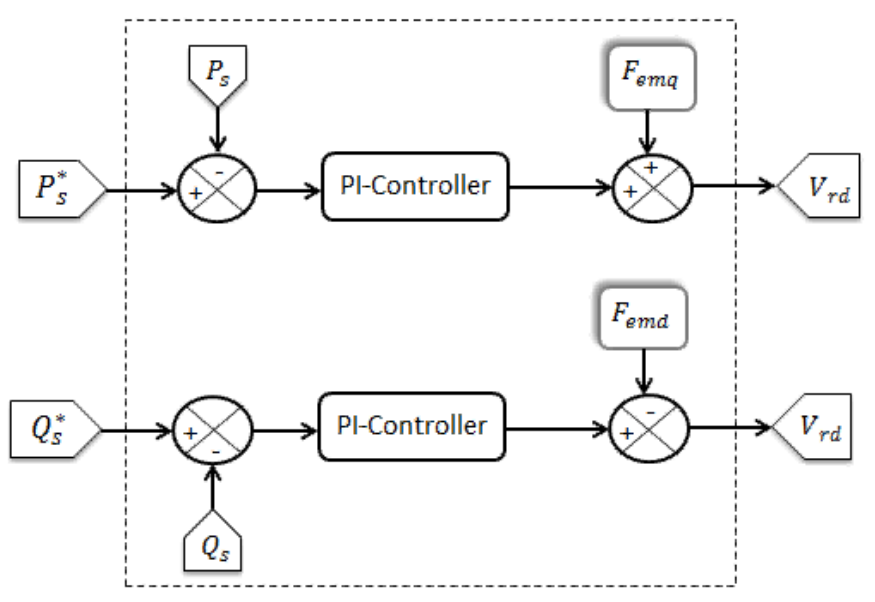

Fig. 9 DDC scenario diagram

\section{B. IDC Scenario}

The second control scenario is called IDC; it takes into consideration the coupling terms $\mathrm{C}_{\mathrm{d}}$ and $\mathrm{C}_{\mathrm{q}}$ and compensates them by setting up four regulators to control the powers and the rotor currents [21], [22]. By combining the different equations of the voltages, rotor currents and the stator powers, we can express the voltages as a function of the powers. The block diagram of the system is reproduced in the opposite direction, to get a model which corresponds to the DFIG control schema. The simplified block diagram of the DFIG control with the two power regulation loops and the current is illustrated in Fig. 10. 


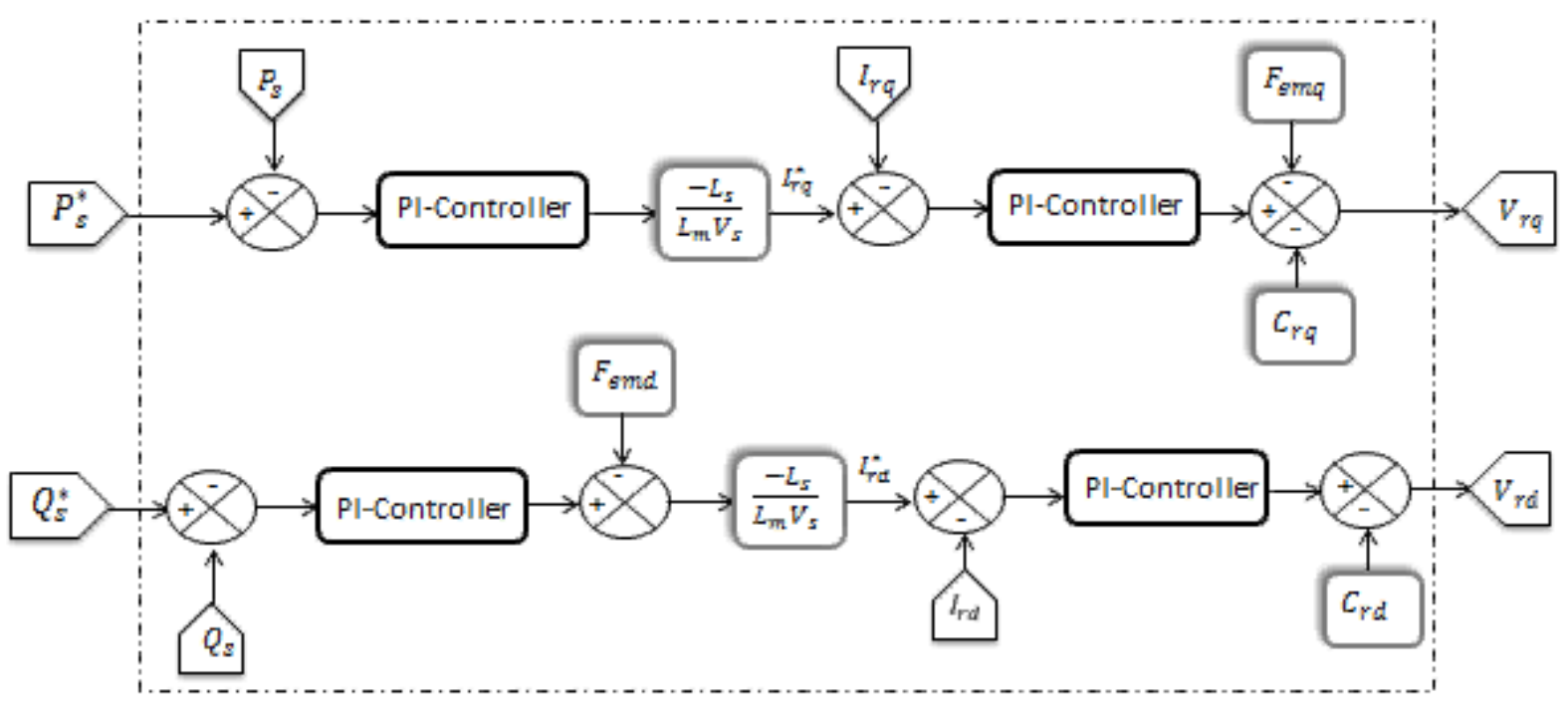

Fig. 10 Direct decoupled control scenario diagram

\section{RESULTS AND DISCUSSION}

In this section, simulations are realized with a $1.5 \mathrm{MW}$ generator connected directly to the stator with a three-phase 50 $\mathrm{Hz}$ frequency grid and a voltage value of $398 \mathrm{~V}$; while its rotor is connected to the grid through two static converters in back-to-back mode. Parameters of the machine are given in appendix. The considered WGS is tested, when the turbine is subject to the wind speed sequence in Fig. 11 (a). This wind speed profile was used in order to evaluate two control scenarios under various conditions.

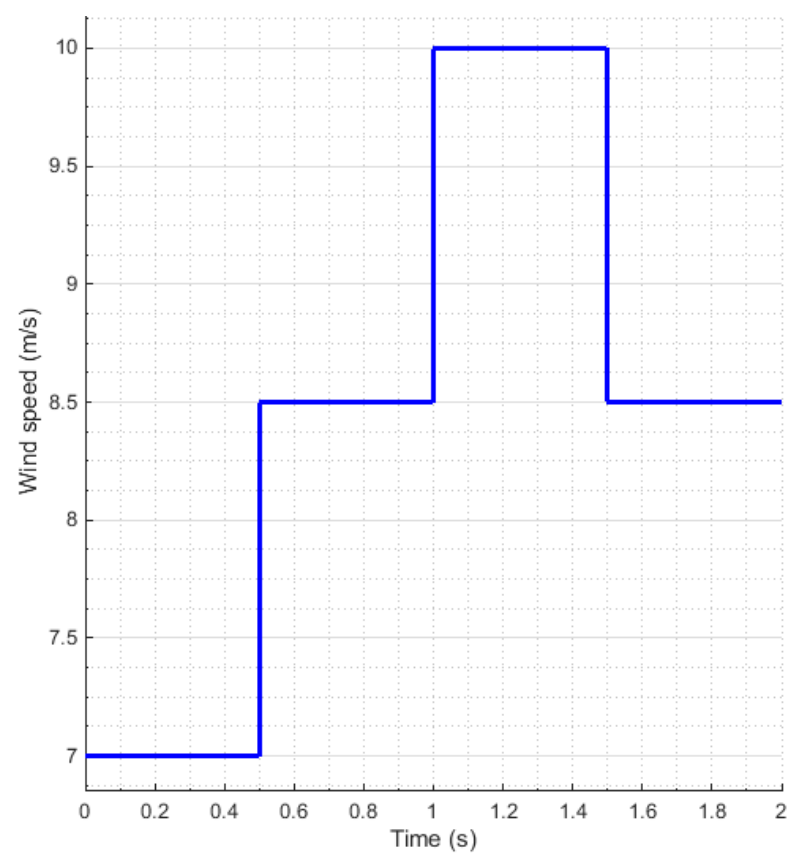

(a)

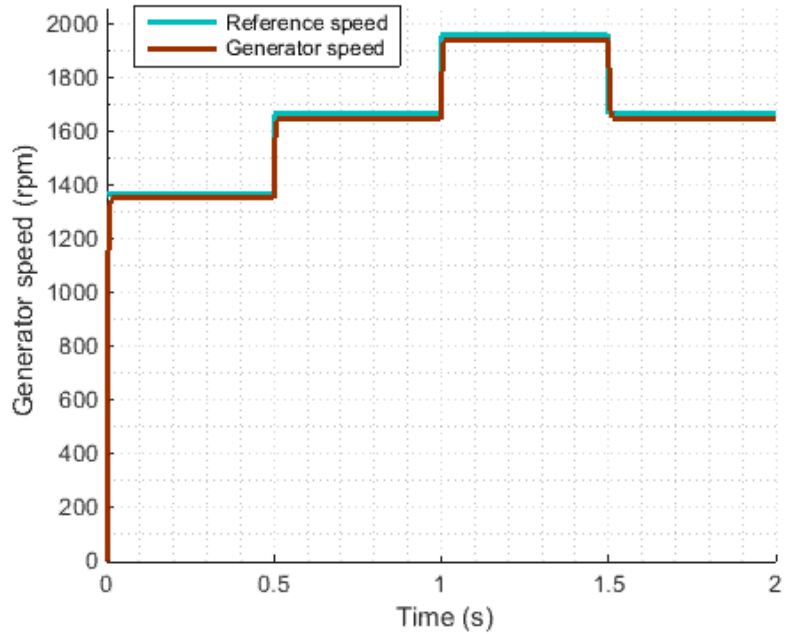

(b)

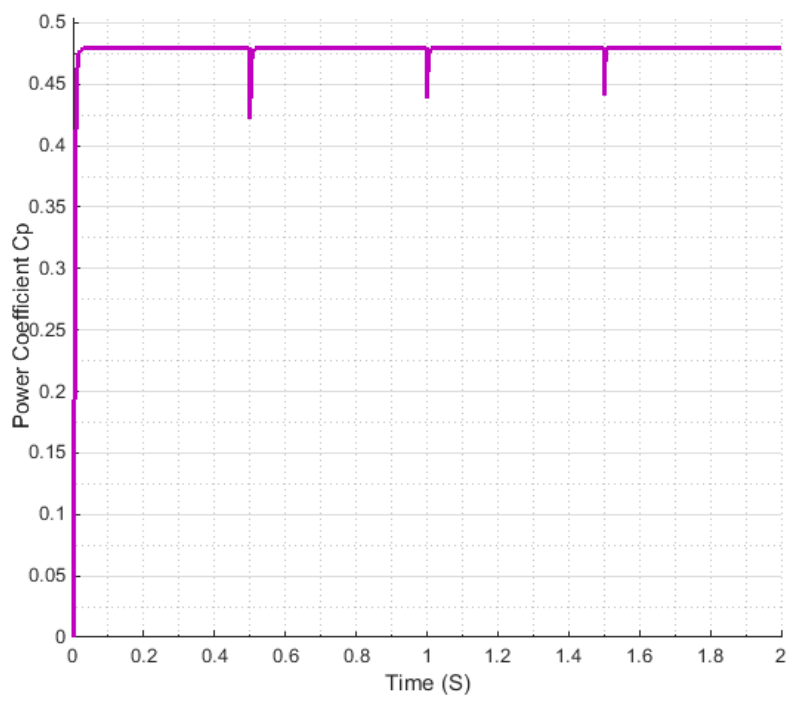

(c) 


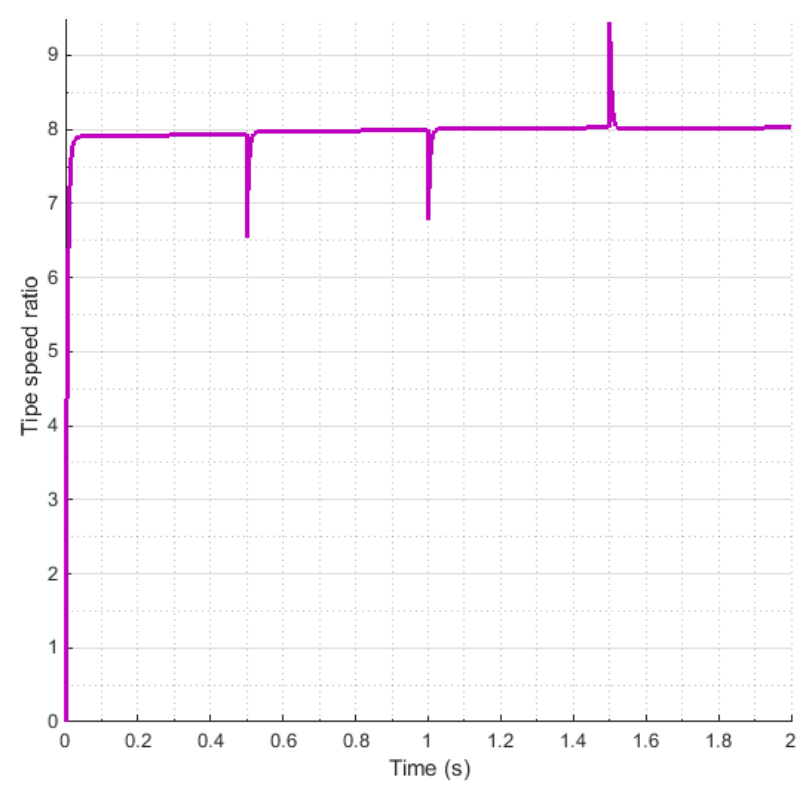

(d)

Fig. 11 (a) Wind speed, (b) generator speed, (c) power coefficient and (d) Tip speed ratio

The mechanical speed of the generator and its reference are shown in Fig. 11 (b), which clearly expresses that the rotational speed of the generator exactly followed its optimal speed. Fig. 11 (c) shows that when the wind speed changes, $\mathrm{C}_{\mathrm{p}}$ will quickly return to its maximum value. The power coefficient is maintained around its optimum $\mathrm{C}_{\mathrm{p}-\max }=0.48$ over the entire range of wind speed, imposing an optimal speed ratio $\lambda_{\text {opt }}=8.1$ as shown in Fig. 11 (d). This means that the control MPPT theory is valid perfectly.

In order to evaluate the performance of the two control scenarios, we performed two categories of tests: references tracking test and robustness test to the machine parameter variations. For both tests, the MPPT command was applied for the entire wind energy conversion chain to extract the maximum power carried by the wind. The DFIG was driven through the gear box by the wind turbine driven by a wind speed whose profile is shown in Fig. 11 (a). To keep the power factor of the wind turbine at it maximum level, the active power reference comes from the generator speed closed loop control according to MPPT control theory; while the reactive power reference changes at the instant $t=1.2 \mathrm{~s}$ from $\mathrm{Q}_{\mathrm{s}}^{*}=5.10^{5}$ VAR to $\mathrm{Q}_{\mathrm{s}}^{*}=-5.10^{5} \mathrm{VAR}$.

\section{A. Reference Tracking}

The objective of this test was to analyze the behavior of system for the two control scenarios in terms of reference tracking. Figs. 12 (a) and (b) respectively represented the results obtained using the direct and indirect control scenarios for DFIG generator control. In response to the considered wind speed profile, the measured active and reactive power of the generator stator showed that the power references were well followed for both control scenarios.


(a) DDC scenario 

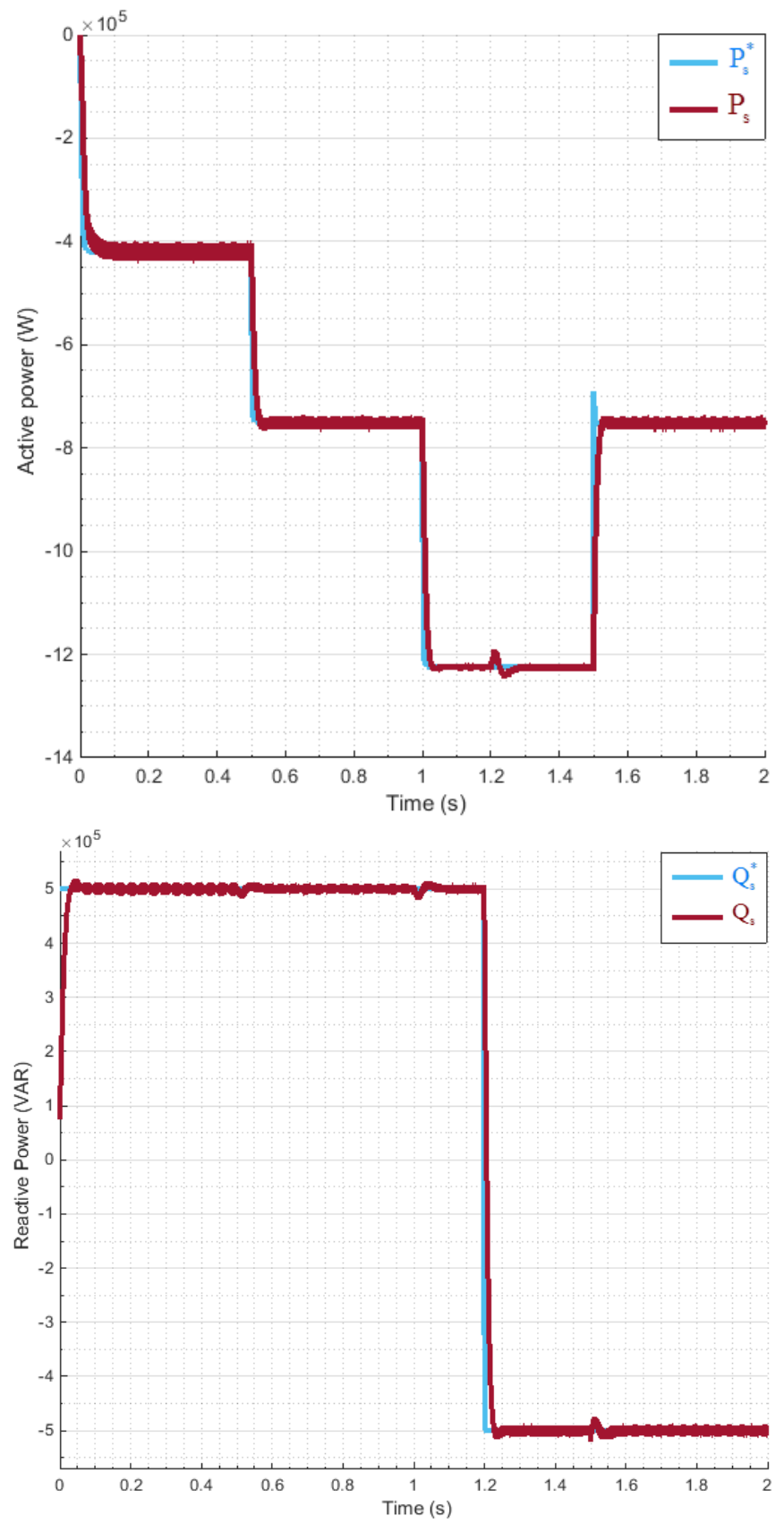

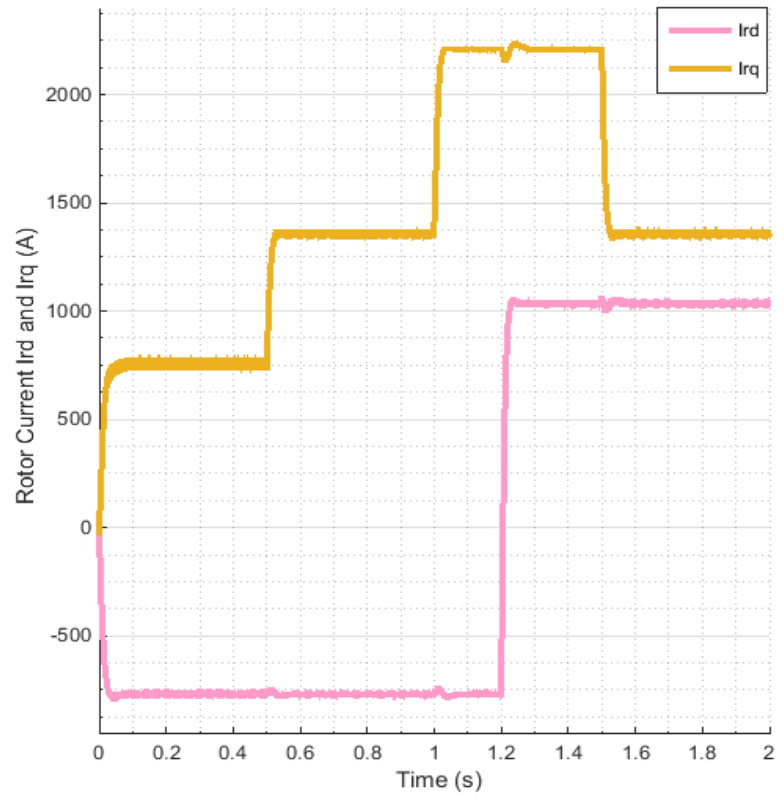

(b) IDC scenario

Fig. 12 Stator active and reactive power responses and the rotor currents in the d-q reference

For IDC scenario the effect of the coupling between the two control axes ( $\mathrm{d}$ and $\mathrm{q}$ ) was observed because all reference change of the one of two powers introduce the small oscillations on the other power. On the other hand, the effect of this variation is negligible in the case of the DDC scenario because the model of the DFIG was simplified by the negligence of the coupling terms.

The direct and quadrature rotor currents respectively have the same image as the stator reactive and active power, as presented in Figs. 12 (a) and (b). This means that the active power was controlled by $I_{r q}$ while the reactive power was controlled by $I_{r d}$. Moreover, the results showed that the waveform of the currents are almost sinusoidal and that the amplitude of the three-phase stator and rotor currents generated by the DFIG was proportional to the active power supplied to the grid as shown in Fig. 13. 

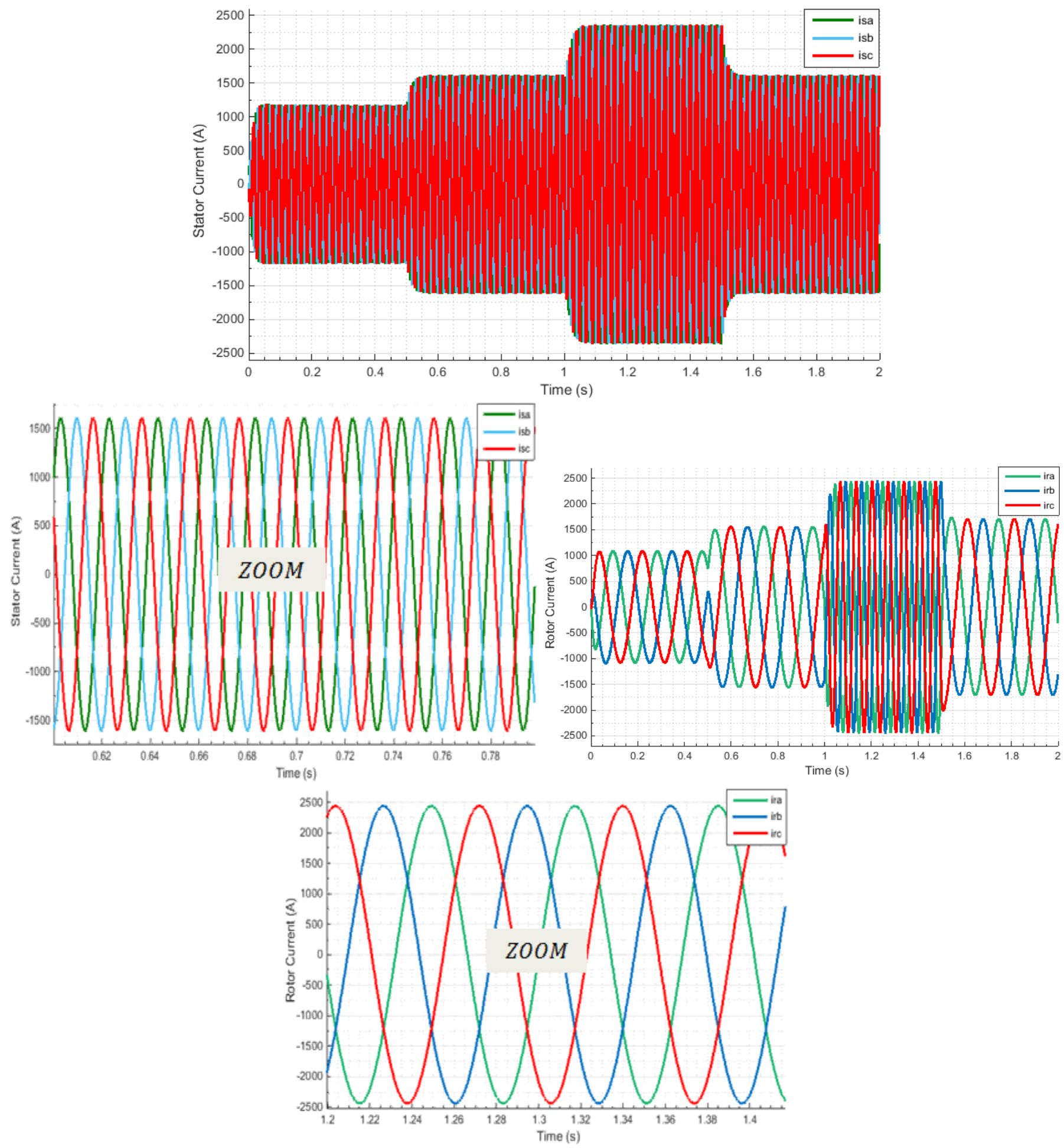

Fig. 13 Three-phase stator and rotor currents

\section{B. Robustness Test}

The parameters of the DFIG generator were subjected to changes caused by various physical phenomena. In order to test the robustness of the two control scenarios, the wind energy system is simulated under the DFIG machine parameters inconstancy.

First test (heating case): Fig. 14 displays the performances of the two control scenarios of the response of the active and reactive powers when the rotor resistance $R_{r}$ was increased to $150 \%$ of its nominal value. With respect to the DDC, the increase in rotor resistance introduced an increase in the response time for both the active power and the reactive power as appears in Fig. 14 (a). Whereas the response of the active and reactive powers are almost insensitive to rotor resistance $R_{r}$ variation in the case of use the IDC control strategy, as show in Fig. 14 (b). 
Second test (magnetic saturation case): Fig. 15 showed the effect of the magnetic saturation on the active and reactive power response for the two control scenarios. In this case, the mutual inductance value $\mathrm{L}_{\mathrm{m}}$ was decreased to $10 \%$ of its value nominal. This variation affected the static and dynamic performance of the DDC scenario. Fig. 15 (a) shows that this sensitivity was reflected via the occurrence of overshoots, as well as via the increase of the response time and the static error of the responses of the active power and the reactive power. On the other hand, IDC scenario partially lost control efficiency, but the decoupling remained as shown in Fig. 15 (b).


(a) DDC scenario
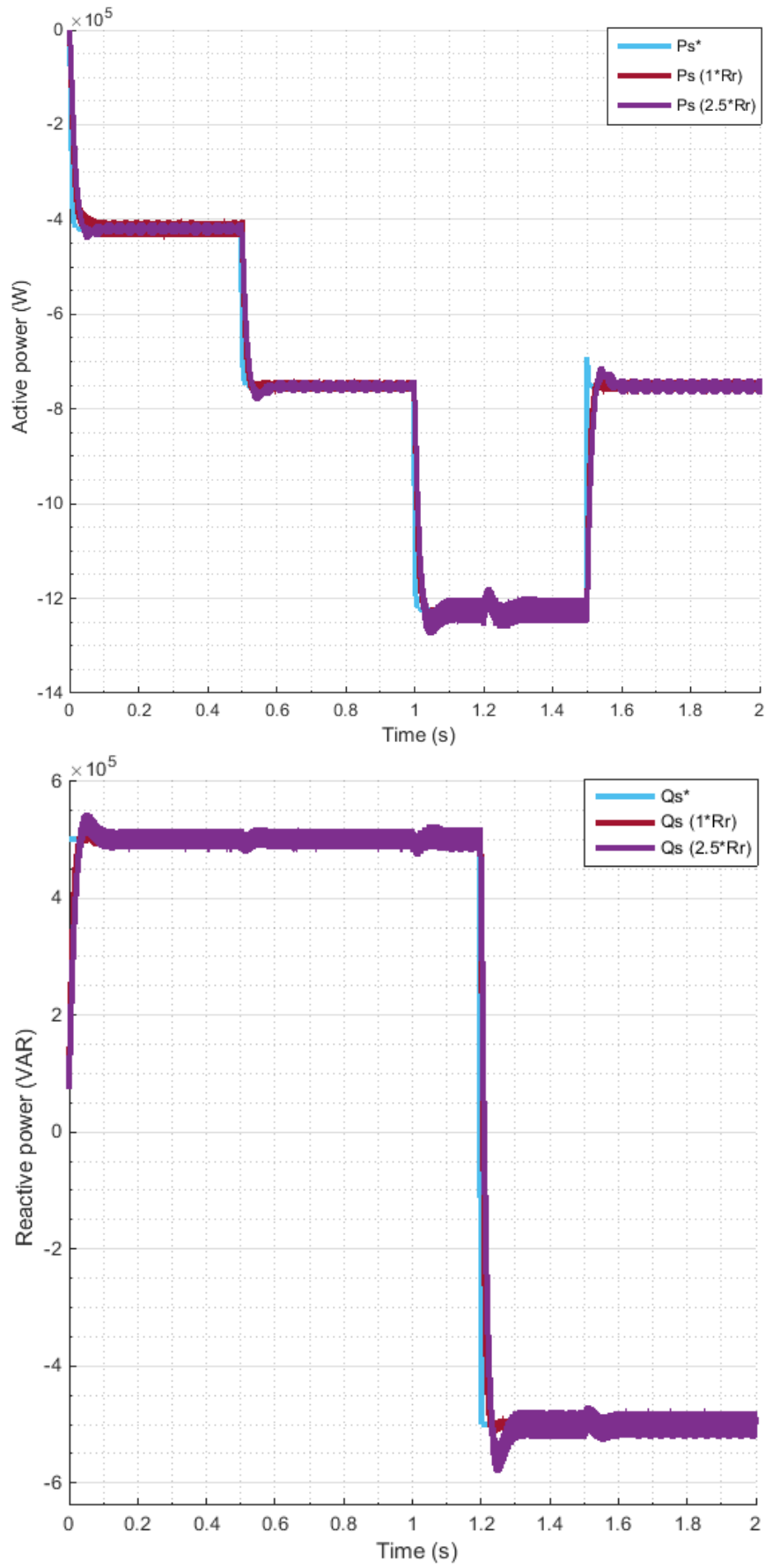

(b) IDC scenario

Fig. 14 Active and reactive power responses with $R_{r}$ variation 



(a) DDC scenario

(b) IDC scenario

Fig. 15 Active and reactive power responses with $L_{m}$ variation

\section{V.CONCLUSION}

In this work, a DFIG-based variable speed WGS has been controlled through two control scenarios. First, we presented the model of the wind energy system, and then we developed direct and IDC scenarios of the active and reactive power of the DIFG generator, in order to control energy exchanges with the electrical network. These both control scenarios presented combines vector control and MPPT control theory in order to 
maximize the generated power from WGS. So as to examine the performances of each control scenario, the system performance was tested and compared by simulation in terms of reference tracking and robustness against the parametric variations of the DFIG. The results obtained showed that the two methods ensured perfect decoupling the powers generated by the DFIG when the powers references change instantaneously. They show also that DDC is the simplest implementation, but not the best efficient. However, the IDC scenario allows us, with the loop cascade, to have a most robust and efficient system. It is assuredly extremely complex implementation compared to DDC scenario, but it has an optimal operation of electrical generation system by reducing probable problems related to parametric variations of the DFIG and the wind system. Thus, the continuation of the work can be designed and have a real implementation of this control scenario in an FPGA.

\section{APPENDIX:}

TABLE I

WIND TURBINE PARAMETERS

\begin{tabular}{ccc} 
Symbol & Quantity & Value \\
\hline $\mathrm{R}$ & Blade radius & $35.25 \mathrm{~m}$ \\
$\mathrm{G}$ & Gearbox ratio & 90 \\
$\mathrm{~J}$ & Moment of inertia & $1000 \mathrm{~kg} \cdot \mathrm{m}^{2}$ \\
$\mathbf{f}_{\text {vis }}$ & Viscous friction & $0.0024 \mathrm{~N} \cdot \mathrm{M.} \mathrm{s}^{-1}$ \\
\multicolumn{3}{|}{} \\
$\mathbf{V}_{\text {in }}$ & coefficient \\
$\mathbf{V}_{\text {out }}$ & Cut-in wind speed & $4 \mathrm{~m} / \mathrm{s}$ \\
$\mathbf{V}_{\mathbf{n}}$ & Cut-out wind speed & $25 \mathrm{~m} / \mathrm{s}$ \\
\hline
\end{tabular}

TABLE II

DFIG parameters

\begin{tabular}{ccc} 
Symbol & Quantity & Value \\
\hline $\mathbf{P}_{\mathbf{n}}$ & Rated power & $1.5 \mathrm{MW}$ \\
$\mathbf{I}_{\mathbf{n}}$ & Rated current & $1900 \mathrm{~A}$ \\
$\mathbf{U}_{\mathbf{D C}}$ & Rated DC-Link voltage & $1200 \mathrm{~V}$ \\
$\mathbf{f}$ & Stator rated frequency & $50 \mathrm{~Hz}$ \\
$\mathbf{L}_{\mathbf{s}}$ & Stator inductance & $0.0137 \mathrm{H}$ \\
$\mathbf{L}_{\mathbf{r}}$ & Rotor inductance & $0.0136 \mathrm{H}$ \\
$\mathbf{L}_{\mathbf{m}}$ & Mutual inductance & $0.0135 \mathrm{H}$ \\
$\mathbf{R}_{\mathbf{s}}$ & Stator resistance & $0.012 \Omega$ \\
$\mathbf{R}_{\mathbf{r}}$ & Rotor resistance & $0.021 \Omega$ \\
$\mathrm{p}$ & Number of pair poles & 2 \\
\hline
\end{tabular}

\section{REFERENCES}

[1] G. Tsourakisa, B. M. Nomikosb and C. D. Vournasa, "Effect of wind parks with doubly fed asynchronous generators on smallsignal stability," Electric Power Systems Research, January 2009, vol.79, pp.190-200.

[2] P. Stumpf and I. Nagy, "Study of Doubly Fed Induction
Generator for Wind Power Application", in: Clean Electrical Power (ICCEP), 2013 International Conference on, 11-13 June ,2013 Alghero, Italy, IEEE, 2013, pp. 1-8

[3] M. Ghofrani, and A. Arabaliin, "Modeling and simulation of a DFIG-based wind-power system for stability analysis," : 2012 IEEE Power and Energy Society General Meeting, July 2012, San Diego, CA, USA, pp. 1-8.

[4] R .Cardenas, R. Pena, J. Proboste, G. Asher and J. Clare, "MRAS observer for sensorless control of standalone doubly fed induction generators", IEEE Transaction on Energy Conversion, December 2005, vol. 20, pp.710-718.

[5] J. Hu, J. Zhu, D.G. Dorrell, Q. Ma, Y. Zhang, W. Xu "Control strategies of variable-speed wind system under new grid code requirement-A survey", IEEE Industrial Electronics Society, Nov. 2010, pp. 3061-3066.

[6] M. Tazi, V. Kumar, R. C. Bansal, S. Kong, Z. Y. Dong, W. Freitas and H. D. Mathur, 'Three-phase doubly fed induction generators: an overview', Electric Power Applications, IET, 2010, vol. 4, pp. 75-89.

[7] W. Hofmann and F. Okafor, "Doubly-Fed Full-Controlled Induction Wind Generator for Optimal Power Utilization," in Proceeding of 4th IEEE International Conference on Power Engineering and Drive Systems 2001, pp. 355-361.

[8] E. Aydin, A. Polat and L. T. Ergene, "Vector control of DFIG in wind power applications," IEEE International Conference on Renewable Energy Research and Applications (ICRERA), Birmingham, UK ,March 2017, pp.478-483.

[9] R. B. Sholapurkar and Y. S. Mahajan, "Review of Wind Energy Development and Policy in India," Energy Technology \& Policy, 2015, vol.1, pp. 122-132.

[10] J. Mwaniki, H. Lin and Z. Dai, "A Condensed Introduction to the Doubly Fed Induction Generator Wind Energy Conversion Systems," Journal of Engineering, June. 2017, pp.1-18.

[11] A. Ishteyaq and S. Rakesh," Doubly Fed Induction Generator Based WECS with the Double Trap LLCL Filter For Harmonics Mitigation", Journal of Engineering Research and Application, 2018, vol. 8, pp. 20-26.

[12] J. Ben Alaya, A. Khedher and M. F. Mimouni, "Steady-State Analysis of DFIG for Wind Power Generation System Drive," INTERNATIONAL JOURNAL OF ENERGY, Vol. 6, 2012, pp.123-132.

[13] M. Kowsalya, S. S. Gaurav, B. N. T. Rao and M. Hareesh, "Modeling of DFIG for the Variable Speed Wind Turbine," International Conference on Control, Instrumentation, Communication and Computational Technologies (ICCICCT), Kanyakumari, India, July 2014, pp. 591-594.

[14] T. Luu, A. Nasiri, "Power Smoothing of Doubly Fed Induction Generator for Wind Turbine Using Ultra capacitors, "IEEE Trans. IECON 2010 - 36th Annual Conference, pp. 3293-3298, 2010

[15] F. Poitiers M. Machmoum R. Le Daeufi and M.E. aim, "Control of a doubly-fed induction generator for wind energy conversion systems, "IEEE Trans .Renewable Energy, Vol. 3, December 2001, pp.373-378.

[16] J. A. Santisteban and R.M. Stephan, "Vector control methods for induction machines: An overview", IEEE transaction on education, 2001, Vol. 44, No. 2.

[17] Benoît Robyns, Bruno Francois, Philippe Degobert, Jean Paul Hautier, Vector control of induction machines, Springer Verlag London 2012

[18] C. Ashish , S. Vishal , C. Abhishek and P. Sakshi," Comparison study of vector control of induction motor using rotor flux estimation by two different methods," International Journal of Electronic and Electrical Engineering, 2014, Vol. 7, N. 3, pp. 201-206 
[19] A. S. M. Tausif, A. R. Umale, R. K. Kirpane, "Vector control methods for variable speed AC motors," International Research Journal of Engineering and Technology, 2017, Vol. 4, pp. 340343.

[20] N. Ramesh Babu and P. Arulmozhivarman, "Wind energy conversion systems-A technical review", Journal of Engineering Science and Technology, 2013, pp. 493 - 507.

[21] M. Boutoubat, L. Mokrani, M. Machmoum. Control of a wind energy conversion system equipped by a DFIG for active power generation and power quality improvement. Renewable Energy 50 (2013), pp. 378-386.

[22] SY. Shao, E. Abdi, F. Barati, R. McMahon. Stator-flux-oriented vector for brushless doubly fed induction generator. IEEE Transactions on Industrial Electronics, 2009, 56(10): 42204228.

\section{Creative Commons Attribution License 4.0 (Attribution 4.0 International, CC BY 4.0)}

This article is published under the terms of the Creative Commons Attribution License 4.0

https://creativecommons.org/licenses/by/4.0/deed.en US 